\title{
Management of uterine leiomyoma with mifepristone and its outcome in South Indian population
}

\author{
Ilangovan Subashree ${ }^{1, *}$, Geetha Prasad ${ }^{2}$ \\ Assistant Professor, Dept. of Obstetrics and Gynaecology, Karpaga Vinayaga Institute of Medical Sciences, Madhurantagam, \\ Tamil Nadu, India \\ *Corresponding Author: \\ Email: subashreeobg@gmail.com
}

Received: $22^{\text {nd }}$ March, 2018

Accepted: $14^{\text {th }}$ May, 2018

\begin{abstract}
Introduction: Uterine Fibroids are common growth of female reproductive tract in women of reproductive age group. So this prospective observational study was conducted to evaluate the effect of low dose Mifepristone treatment for 6 months on the outcome of fibroid size and related symptom.

Materials and Methods: The study was a prospective observational study conducted at Tertiary care Hospital, Tamil Nadu during the period of July 2016 to June 2017. Forty five patients with symptomatic fibroid, aged between 24-45 years were recruited for the study. Baseline data regarding fibroid volume, Hb value, PBAC (Pictorial Blood Assessment Chart) \& VAS (Visual analogue Scheme) score were recorded. The follow-up data regarding above parameters again collected at the end of 6 months of therapy. All patients received $25 \mathrm{mg}$ mifepristone daily and comparison was made between pre and post treatment symptoms and leiomyoma volume.

Results: After therapy with Mifepristone there was a significant reduction in mean volume of fibroid, menorrhagia and pain related symptoms. The mean leiomyoma volume was reduced from $104.3 \mathrm{~mm}^{3}$ to $56.8 \mathrm{~mm}^{3}$ by the end of 6 months of mifepristone therapy. Similarly, at the end of six months of therapy mean hemoglobin value was also raised by $2.8 \mathrm{gm} / \mathrm{dl}$ from the baseline mean value of $7.9 \mathrm{gm} / \mathrm{dl}$. There were no major side effects observed during the course of the study and the drug was well tolerated.

Conclusion: Mifepristone is effective against low size uterine leiomyoma and can decrease its associated symptoms among women with symptomatic fibroids.
\end{abstract}

Keywords: Mifepristone, Leiomyoma, Clinical treatment, Menorrhagia, Dysmenorrhea, Uterine fibroid, Volume of fibroid, Leiomyoma.

\section{Introduction}

Uterine leiomyoma is the common problem seen in reproductive age group and perimenopausal group women which account upto $40 \%$ of all hysterectomies. ${ }^{1}$ Symptoms of leiomyoma include menstrual irregularity, menorrhagia, dysmenorrhea, pelvic pain, infertility etc. Recent studies on the effectiveness of various modes of non surgical management for the treatment of uterine leiomyomas have shown positive outcome. ${ }^{1,2}$ Assessment of symptoms associated with fibroids reveals that progesterone receptor modulators are effective and the improvement in menstrual problems is associated with improved quality of life. Over a recent years evidence has grown that progesterone and its receptor play a key role in fibroid growth and development. ${ }^{3}$ Mifepristone is a selective progesterone receptor binding modulator with primary antagonist properties. ${ }^{4-6}$ Observational studies on leiomyoma treated with mifepristone have shown that it is effective in managing leiomyoma. Mifepristone is effective by causing reduction of their size and producing relief in symptoms. $^{5-8}$ In many placebo control trials of mifepristone has been shown to decrease myoma size and as well symptoms. ${ }^{2,7-9}$ So this prospective observational study was conducted to evaluate the effect of low dose mifepristone treatment for 6 months on the outcome of fibroid size and related symptoms. The present study is undertaken to evaluate efficacy and safety of mifepristone in the management of uterine leiomyoma.

\section{Materials and Methods}

The study was conducted at Karpaga Vinayaga Institute of Medical Sciences and Research Center, Madhurantagam, Tamil Nadu during the period of July 2016 to June 2017. This study includes comparison of data before and after treatment with Mifepristone and its outcome on leiomyoma volume and related symptoms. First ultrasound was done at the initiation of treatment noting the size and volume of fibroid and the endometrial thickness was done in all patients. All the patients received $25 \mathrm{mg}$ mifepristone daily. Second ultrasound was done after six months of treatment with mifepristone. Comparison of data between pre and post treatment, with respect to associated symptoms and size, volume of leiomyoma and increase in endometrial thickness was done.

Patients with symptomatic uterine leiomyomas in reproductive and perimenopausal age group without endometrial hyperplasia were recruited for the study. The exclusion criteria included women with systemic health problems like severe anemia and acute 
symptoms, presence of pregnancy or lactation, evidence of ovarian, cervical or uterine malignancy, history of hormonal treatment in the past three months, histopathological evidence of endometrial hyperplasia, presence of liver, respiratory (asthma), renal, heart disease, pelvic inflammatory disease or any other adnexal pathology and patient necessitating early surgical intervention for uterine leiomyoma. The study was approved by the institutional ethics committee. The written informed consent was obtained from all the patients after explaining the purpose of the study. History of the patient like menorrhagia, dysmenorrhoea, pelvic pressure, pelvic pain, low backache, rectal pressure, and urinary frequency was obtained by questionnaire. Severity of the symptoms was graded according to the visual analog scale and blood loss quantification was done using Pictorial blood loss assessment chart (PBAC). ${ }^{10-12}$

Ultrasound evaluation involved measurement of uterine volume, leiomyoma volume. Viscosmi formula was used for the calculation of average uterine volume, that is, $4 / 3 \prod \mathrm{W} / 2 \times \mathrm{L} / 2 \times \mathrm{T} / 2$, where $\mathrm{W}$ is uterine width on transverse section passing through the uterine fundus; $L$ is uterine length, measured on sagittal section from internal cervical os to fundus. $\mathrm{T}$ is uterine thickness measured on sagittal section between the anterior and posterior walls. ${ }^{14-15}$ Assessment of average leiomyoma volume was done by the formula 4/3 П $\mathrm{ABC}$, where $\mathrm{ABC}$ represent radii of the sphere in three dimensions. In cases of multiple fibroids, average volume of all the leiomyoma was taken. Volume of the largest leiomyoma calculated as above was also taken as an index parameter. Endometrium was biopsied in premenstrual phase at the start of the therapy.

Patients were enquired regarding their blood loss by PBAC and leiomyoma related symptoms. Measurements including uterine volume, leiomyoma volume and largest leiomyoma volume were repeated each month. Note of serum biochemistry, that is haemoglobin, liver function tests and kidney function tests and side-effects, such as nausea, vomiting, diarrhea, headache, fatigue, hot flushes was also made. Endometrial biopsy was repeated after six months of treatment with mifepristone.

In this study 45 patients with symptomatic leiomyomas were treated with $25 \mathrm{mg}$ mifepristone daily for six months to note clinical improvement in symptoms and radiological decrease in fibroid volume. After this time period improvement in menorrhagia and pain in lower abdomen were noted. Also recorded the initial ultrasound volume of the fibroid and reduction in volume after six months of treatment. Development of untoward effects of mifepristone was also noted, namely endometrial hyperplasia. The information accumulated by treating 45 patients with mifepristone was then plotted in tables and charts for the ease of statistical analysis. Finally all the data was analysed to determine whether mifepristone caused any significant improvement in symptoms of patients or significant reduction in the volume of leiomyoma radiologically. One way analysis of variance was used to find out the statistical significance after treatment.

\section{Results}

The commonest presenting symptoms of the patients were menorrhagia and pain lower abdomen. Though more than half of the patients had small fibroids with volumes $<100 \mathrm{~cm}^{3}, 22 \%$ had quite large ones some even measuring $>500 \mathrm{~cm}^{3}$.

The study showed $100 \%$ improvement of menorrhagia as all the 45 patients with heavy bleeding were rendered amenorrhoeic during the treatment with mifepristone.

Table 1 shows the baseline characteristics of studied population. Table 2 shows the comparison of pain related symptoms in patients with leiomyoma before and after treatment with mifepristone. From table 2 and table 3 it is evident that there is improvement with respect to pain related symptoms, and reduction in volume of uterine myoma is observed in the present study. Table 4 and table 5 shows percentages in reduction in pain related symptoms and reduction in volume of myoma after treatment with mifepristone.

Mean PBAC score was reduced from 102.6 to 9.2 by the end of 6 months of therapy. There was significant decrease in pain related symptoms 16 women out of 32 after six months of treatment with mifepristone. At the end of six months of therapy hemoglobin mean value was also raised by $2.38 \mathrm{gm} / \mathrm{dl}$ from the baseline mean value of $7.9 \pm 0.9 \mathrm{gm} / \mathrm{dl}$. There were no major side effects during the course of the study and treatment was well tolerated.

The associated endometrial change such as hyperplasia does not appear to occur with short use. In the present study after starting the treatment there was reduction in menstrual blood loss observed in $90 \%$ of patients and $75 \%$ of patients attained amenorrhea at the end of treatment. There is an improvement in haemoglobin parameter in the study group. The size of fibroids was also decreased and resistive index after treatment was raised due to loss of blood supply. PBAC reduced significantly from 102.6 to 9.2 after starting the treatment and effect was noticed in the consequent menstrual cycles. 
Table 1: Baseline characteristics of study subjects $(n=45)$

\begin{tabular}{|l|c|}
\hline \multicolumn{1}{|c|}{ Parameter } & Mean \pm SD \\
\hline Age $($ years $)$ & $33.2 \pm 5.4$ \\
\hline BMI $\left(\mathrm{Kg} / \mathrm{m}^{2}\right)$ & $27.9 \pm 2.4$ \\
\hline Parity & $2.5 \pm 1.5$ \\
\hline Duration of symptoms (in months) & $7.8 \pm 6.2$ \\
\hline PBAC score & $102.6 \pm 30.5$ \\
\hline VAS score & $6.5 \pm 1.2$ \\
\hline Fibroid Volume $\left(\mathrm{cm}^{3}\right)$ & $104.3 \pm 66.4$ \\
\hline Hemoglobin $(\mathrm{gm} / \mathrm{dl})$ & $7.9 \pm 0.9$ \\
\hline
\end{tabular}

Table 2: Comparison of pain related symptoms at first visit and at six months after mifepristone

\begin{tabular}{|l|c|c|c|c|}
\hline \multirow{2}{*}{ Symptoms } & \multicolumn{2}{|c|}{ Before treatment } & \multicolumn{2}{c|}{ After 6 months of treatment } \\
\cline { 2 - 5 } & $\mathbf{n}$ & $\mathbf{\%}$ & $\mathbf{n}$ & $\mathbf{\%}$ \\
\hline Menorrhagia & 20 & 44.4 & 8 & 17.8 \\
\hline Dysmenorrhoea & 12 & 26.6 & 4 & 8.8 \\
\hline Pelvic pain & 10 & 22.2 & 3 & 6.6 \\
\hline Back ache & 2 & 4.6 & 1 & 2.2 \\
\hline Urinary retention & 1 & 2.2 & 0 & - \\
\hline & 45 & & 16 & \\
\hline
\end{tabular}

Table 3: Comparison of fibroid volume at first visit and follow-ups after mifepristone

\begin{tabular}{|l|c|c|c|c|}
\hline \multirow{2}{*}{ Volume of myoma } & \multicolumn{3}{|c|}{ Before treatment } & \multicolumn{2}{c|}{ After 6 months of treatment } \\
\cline { 2 - 5 } & $\mathbf{n}$ & $\mathbf{\%}$ & $\mathbf{n}$ & \% \\
\hline$\leq 50$ & 13 & 28.9 & 12 & 26.6 \\
\hline $51-100$ & 15 & 33.3 & 9 & 20 \\
\hline $101-150$ & 10 & 22.2 & 2 & 4.4 \\
\hline $151-200$ & 4 & 8.9 & - & - \\
\hline$>200$ & 3 & 6.7 & - & - \\
\hline Mean \pm SD & \multicolumn{2}{|l}{$104.3 \pm 66.4$} & \multicolumn{2}{|c|}{$56.8 \pm 27.3$} \\
\hline
\end{tabular}

Table 4: Reduction in pain after treatment

\begin{tabular}{|l|c|c|}
\hline Pain reduction after treatment & No. of patients & Percent \\
\hline $0-20 \%$ & 4 & 8.8 \\
\hline $21-40 \%$ & 8 & 13.3 \\
\hline $41-60 \%$ & 12 & 26.6 \\
\hline $61-80 \%$ & 10 & 22.2 \\
\hline $81-100 \%$ & 13 & 28.9 \\
\hline
\end{tabular}

Table 5: Comparison of fibroid volume at first visit and follow up after mifepristone treatment

\begin{tabular}{|l|c|c|}
\hline $\begin{array}{l}\text { Reduction in volume of } \\
\text { myoma after treatment }\end{array}$ & No. of patients & Percent \\
\hline $0-20 \%$ & 1 & 2.2 \\
\hline $21-40 \%$ & 4 & 8.9 \\
\hline $41-60 \%$ & 3 & 6.7 \\
\hline $61-80 \%$ & 7 & 15.5 \\
\hline $81-100 \%$ & 30 & 66.7 \\
\hline
\end{tabular}

\section{Statistical Analysis}

The data obtained from the study was noted. Mean and standard deviation of the studied parameters were mentioned in tables for the ease of statistical analysis. Finally all the data was analysed using SPSSS 16.0 to determine whether mifepristone caused any significant improvement in symptoms of patients or significant reduction in the volume of leiomyoma radiologically.
McNemar Chi Square test and Wilcoxon signed rank analysis to determine the significance level of the study was done.

\section{Discussion}

Excessive vaginal bleeding was the main problem for the all the women recruited for the study, compelling them to visit health care facilities, as it 
affected their day to day activities; health status \& work efficiency. This symptom was reported by $82 \%$ cases, followed by backache \& pain abdomen by $72 \%$ \& 52\% cases, respectively.

Mifepristone, as a treatment option for myoma, was first reported by Murphy et al in $1993 .{ }^{6}$ Further studies evaluated mifepristone in doses varying from 2.5 to $50 \mathrm{mg} /$ day given for 3 to 6 months and doses as high as $50 \mathrm{mg}$ and as low as $5 \mathrm{mg}$ were found effective in ameliorating myoma related symptoms like dysmenorrhoea, menorrhagia and pelvic pressure, and reducing myoma volume by $26-57$ per cent and inducing amenorrhoea in 41-100 per cent ${ }^{6,15,16-18}$ Ultra low dose of $2.5 \mathrm{mg}$ also resulted in appreciable symptomatic relief, modest 11 per cent reduction in uterine volume suggesting a possible dose effect with improvement in quality of life. . $^{, 10,13-15}$

Current studies support that growth of myoma in humans is progesterone dependent also and therefore antiprogestins (Mifepristone) and selective progesterone receptor modulators (SPRMs-Asoprisnil) can be effective in treatment. ${ }^{16-18}$ Hormonal treatment reduces size, improves hemoglobin by controlling bleeding and renders surgery unnecessary as patient reaches menopause, because fibroid being a hormone depended tumor stops to grow after menopause.

Clinical trials using 5-50 $\mathrm{mg}$ doses of mifepristone were conducted for varying periods between 3 to 12 months but exact dose and the duration are yet to be determined. Eisinger, et al., reported fall of $48 \%$ in mean uterine volume while amenorrhoea in $61 \%$ only after 6 months of $10 \mathrm{mg}$ mifepristone. ${ }^{8,9}$ Another study by Kapur A et al., reported amenorrhoea in $40-70 \%$ over one year at $5-10 \mathrm{mg}$ dose, while $100 \mathrm{mg}$ led to $100 \%$ amenorrhoea. ${ }^{3}$ AUB is the main reason of worry in women as it affects their daily routines, work efficiency and health status, therefore mostly opt for hysterectomy as one time management in developing countries. With higher doses speedy and better control of bleeding is achieved, this improves the general condition of women and hemoglobin levels, relieves anxiety and provides women a sense of well being and affectivity of treatment but produce hot flushes and other anti-glucocorticoid side-effects. Murphy et al. had a comparative study of $5 \mathrm{mg}, 25 \mathrm{mg}$ and $50 \mathrm{mg}$ dosage and suggested $25 \mathrm{mg}$ to be the most effective dose to cause clinically significant decrease in leiomyoma volume. ${ }^{6,15}$ We chose $25 \mathrm{mg}$ daily to achieve rapid symptomatic improvement (improved compliance with low dropout rate) in a period of six months with minimal side effects. ${ }^{17-20}$

The fibroid volume was reduced by $27 \%$ and $58 \%$ at the end of 1 st month and 3rd month, respectively. Fibroid volume reduced significantly from baseline to the end of treatment $(p<0.006)$. Mechanism of reduced bleeding and myoma size is likely to be due to structural, functional and micro vascular effects of Mifepristone on the endometrium and uterine musculature in dose and duration dependent manner. In our study $25 \mathrm{mg}$ Mifepristone reduced uterine size to $63.69 \%$ of baseline (-36.4\% decline) while Eisinger et al., $11 \%$ with ultra low $2.5 \mathrm{mg}$ over 6 months. ${ }^{8,9}$

The amount of bleeding was recorded using PBAC scoring system during all visits. PBAC score was reduced by $98 \%$ at end of six months. Reduction in PBAC score was significant from baseline to the end of treatment $(p<0.0001) \&$ effect started from the first follow-up. This is due to suppressive effect of Mifepristone on endometrial and vasculature. In this study conducted by V. Kulshreshtha et al, PBAC score was reduced to $92.4 \%$ and $96.4 \%$ while, $95.7 \%$ and $90.4 \%$ of patients developed amenorrhoea in $10 \mathrm{mg}$ and 25mg Mifepristone group, respectively. ${ }^{12}$ These results are comparable to our study.

The patients were followed for 6 months for amount of pain felt, on a pain analogue scale. There was $90 \%$ reduction in pain score at end of the therapy, in our study. Backache was reported by $79 \%$ of patients at start, which was reduced to less than $20 \%$ at the end of therapy. There was a significant reduction in complain of backache at the end of therapy. Improvement in other pain related symptoms were decreased significantly $(\mathrm{P}<0.001)$. In our study hemoglobin value was raised by $57 \%$ at the end of treatment. Improvement in hemoglobin value was significant in our study ( $\mathrm{p}$ value 0.0001 ). At the end of therapy hemoglobin value was raised by $2.38 \mathrm{gm} / \mathrm{dl}$ from the baseline value of $7.90 \pm 0.9 \mathrm{gm} / \mathrm{dl}$. Similar results were noticed by Seth $\mathrm{S}$ et al, ${ }^{1}$ Sinha $\mathrm{M}$ et al, ${ }^{16}$ he observed that $\mathrm{Hb}$ values were raised by $2.8 \mathrm{gm} / \mathrm{dl}$ at the end of therapy.

\section{Conclusion}

Important and useful effect of mifepristone found in this study was, the control of bleeding leading to improvement in $\mathrm{Hb}$. From this study it can be concluded that mifepristone can be used in treating symptomatic women with uterine leiomyoma, with menorrhagia awaiting surgery to improve anemia, and to reduce the size of tumors to make the surgery technically easier. Low dose Mifepristone showed a speedy and better control of bleeding and alleviation of pain related symptoms that improved general condition of women with few side effects like endometrial hyperplasia.

\section{Conflict of Interest: None declared}

Financial Support: We did not receive any external funding for this project.

\section{References}

1. Seth S, Singh E, Mathur AS, Gupta G. Low dose Mifepristone $(25 \mathrm{mg})$ in treatment of uterine myoma, in perimenopausal women. J South Asian Feder Menopause Soc. 2013;1(1):34-7. 
2. Marino JL, Eskenazi B, Warner M, Samuels S, Vercellini $\mathrm{P}$, Gavoni N, et al. Uterine leiomyoma and menstrual cycle characteristics in a population-based cohort study. Hum Reprod. 2004;19:2350-5.

3. Kapur A, Angomchanu R, Dey M. Efficacy of Use of Long-Term, Low-Dose Mifepristone for the Treatment of Fibroids. The Journal of Obstetrics and Gynecology of India. (September-October 2016) 66(S1):S494-S498.

4. Breech LL, Rock JA. Leiomyomata uteri and myomectomy. In: Rock JA, Jones III HW, editors. Te Linde's operative gynecology. $10^{\text {th }}$ ed. New Delhi: Wolters Kluwer Pvt Ltd; 2010. p. 687-726.

5. Carbonell JL, Acosta R, Perez Y, et al. Safety of $10 \mathrm{mg}$ versus $5 \mathrm{mg}$ of Mifepristone during 9 months for the treatment of uterine fibroids. Double-blind randomized clinical trial. Int J Women's Health. 2013;5:115-24.

6. Murphy AA, Kettel LM, Morales AJ et al. Regression of uterine leiomyomata in response to the antiprogesterone RU486. J Clin Endocrinol Metab. 1993;76(2):513- 17.

7. DeCherney AH, Maheux R, Polan ML. A medical treatment for myomata uteri (Abstract). Fertil Steril. 1983;39:429.

8. Eisinger HS, Meldrum S, Fiscella K et al. Low dose mifepristone for uterine leiomyoma. Obstet Gynecol. 2003;101:243-50.

9. Eisinger SH, Bonfiglio T, Fiscella K, Meldrum S, Guzick DS. Twelve month safety and efficacy of low dose mifepristone for uterine myomas. J Minim Invasive Gynecol. 2005;12:227-33.

10. Fiscella K, Eisinger HS, Meldrum S et al. Effect of mifepristone for symptomatic leiomyomata on quality of life and uterine size. Obstet Gynaecol. 2006;108:138187.

11. Coutinho EM, Boulanger GA, Goncalver MT et al. Regression of uterine leiomyomas after treatment with gestrinone, an antiestrogen, antiprogesterone. Am J Obstet Gynecol. 1986;155:761-67.

12. Kulshrestha V, Kriplani L, Agarwal N, et al. Low dose Mifepristone in medical management of uterine leiomyoma - an experience from a tertiary care hospital from north India. Indian J Med Res. 2013;137:1154-62.

13. Matta WH, Shaw R, Nye M. Long term follow up of patients with uterine fibroids after treatment with the LHRH agonist buserelin. Br J Obstet Gynaecol. 1989;96:200-6.

14. Mukherjee S, Chakraborty S. A study evaluating the effect of Mifepristone (RU 486) for the treatment of leiomyomata uteri. Niger Med J. 2011;52(3):150-2.

15. Murphy AA, Morales AJ, Kettel LM et al. Regression of uterine leiomyomata to the anti-progestrone RU 486: Dose response effect. Fertil Steril. 1995;64(1):187-90.

16. Sinha M. Kayal A, Mukhopadhay P. Effecitveness of mifepristone in the treatment of uterine leiomyomata. $N \mathrm{~J}$ obstet Gynecol. 2013;8(1):22-5.

17. Reinsch RC, Murphy AA, Morales AJ, Yen SS. The effects of RU486 and leuprolide acetate on uterine artery blood flow in the fibroid uterus: A prospective, randomized study. Am J Obstet Gynecol. 1994;170: 1623-27.

18. Yang Y, Zheng S, Li K. Treatment of uterine leiomyoma by two different doses of mifepristone (abstract). Zhonghua Fu Chan Ke Za Zhi. 1996; 31: 624-6.

19. Lippman SA, Warner M, Samuels S, Olive D, Vercellini $\mathrm{P}$, Eskenazi B. Uterine fibroid and gynecologic pain symptoms in a population-based study. Fertil Steril. 2003;80:1488-94.

20. Gross KL, Stovall DW, Chavez NL et al. Management options for uterine fibroids. Clin Obstet Gynaecol. 2001;44:335-85.

How to cite this article: Subashree I, Prasad G, Management of uterine leiomyoma with mifepristone and its outcome in South Indian population. Ind $\mathbf{J}$ Obstet Gynecol Res. 2018;5(3):384-388. 